\title{
Retrograde amnesia due to spreading cortical depression: Paradoxical effect of shock-SD interval'
}

RONALD G. RABEDEAU?

\author{
QUEEN'S UNIVERSITY, CANADAA
}

The effect of spreading cortical depression (SD) on a previously administered one-trial passive avoidance problem was studies in 75 rats. A nonmonotonic relation between the degree of amnesia and the shock-SD interval was observed with greatest amnesia at an intermediate interval. These results are not consistent with a simple consolidation hypothesis but can be explained by a three stage information storage process.

In studies by Pearlman \& Jarvik (1961) and Bureš \& BureSová (1963) it was found that spreading cortical depression produced amnesia for immediately preceding events. These results, in common with similar effects of electro-convulsive shock (Madsen \& McGough, 1961) and certain anesthetic agents (Pearlman, Sharpless, \& Jarvik, 1961), have been interpreted as evidence for a physiological consolidation theory of learning.

One complication of the hypothetical consolidation process is that the degree of amnesia should be inversely related to the length of the interval between training and the amnesia producing event. This relationship has been demonstrated for ECS (Heriot \& Coleman, 1962) and for anesthetics (Pearlman, Sharpless, \& Jarvik, 1961). However, in an unpublished study by Nutter, a nonmonotonic relation between the degree of amnesia and the interval between training and the onset of SD was obtained. That is, a substantial and statistically significant degree of amnesia was found with intermediate intervals. Very long and very short training-SD intervals produced no significant amnesia. The failure to obtain retrograde amnesia with a short training-SD interval is not consistent with a simple consolidation hypothesis.

The present study was designed to replicate Nutter's original finding. A one-trial passive avoidance training procedure similar to that employed by Bureš \& Burešova (1963) was used.

Method

The Ss were 75 adult male albino rats of the SpragueDawley strain. All animals were subject to the same surgical procedures. Under Nembutal anesthetic the skull was exposed, cleared, and dried. Holes $3 \mathrm{~mm}$ in diameter were drilled bilaterally into the skull with the centers approximately $3 \mathrm{~mm}$ lateral to the saggital suture and $2 \mathrm{~mm}$ posterior to the coronal suture. Cannulas were made from polyethylene tube (PE 280) approximately $1 \mathrm{~cm}$ long with one end flared by heating. The flared end was placed on top of the skull surrounding a drill hole and secured with dental cement and small screws fixed to the skull. One end of a fine polyethylene tube (PE 10) about 5 in. long was held in the cannula with a Plexiglas plug. This arrangement permitted the introduction of solutions into the cannula by injecting through the flexible tube with a minimum of disturbance to the animal. A small hole in the Plexiglas plug provided an exit for the solution in the cannula when a new solution was applied.

At the end of the operation, the cannulas were filled with Ringer's solution. They were flushed with fresh Ringer's solution at least once per day before the experimental treatments were applied. At least one day was allowed for recovery from the operation before the first behavioral test.

The test apparatus consisted of a large white compartment (16 in. $x 16$ in.) and a small black compartment (10 in. $x 3$ in.) separated by a small ( 3 in. $x 3$ in.) guillotine door. Each $\mathrm{S}$ was allowed to explore the large compartment for $2 \mathrm{~min}$. with the door closed. Then the door was opened and for $3 \mathrm{~min}$. the $\mathrm{S}$ was allowed to move freely between the two compartments. The amount of time spent in the large compartment during the last 3 min. of the test was recorded for each S. All Ss were given two daily tests before treatment and one test $48 \mathrm{hr}$. after treatment.

The $75 \mathrm{Ss}$ were randomly assigned to five equal groups. Two control groups (S-NSD and NS-SD) assessed the effects of shock alone and SD alone on performance. Immediately after the second pretreatment test, Ss in Group S-NSD were confined in the small compartment and given a 10-sec. foot shock ( 3 ma $300 \mathrm{VAC}$ ). They were then removed from the apparatus and their cannulas were flushed with Ringer's solution. Animals in the SD control group (NS-SD) were removed from the apparatus immediately after the second pretreatment test and their cannulas were filled with a $25 \%$ solution of $\mathrm{KCl}$. Four $\mathrm{hr}$. after application, the $\mathrm{KCl}$ was removed by injecting Ringer's solution through the cannulas. Three experimental groups were used to assess the effects of shuch followed at different intervals ( $1 \mathrm{~min} ., 16 \mathrm{~min}$., and $256 \mathrm{~min}$.) by SD. The S-SD 16 and S-SD 256 Ss were returned to their home cages in the interval before application of $\mathrm{KCl}$. The S-SD 1 Ss were placed on a table and the procedure for applying $\mathrm{KCl}$ was instituted almost immediately.

\section{Results}

The results, in terms of the mean time spent in the large compartment for the tests just before and $48 \mathrm{hr}$. after treatment, are shown in Fig. 1. Pretreatment means did not differ significantly $(F=1.26, d f=4 / 70)$. Post-treatment differences were highly reliable $(F=$ 


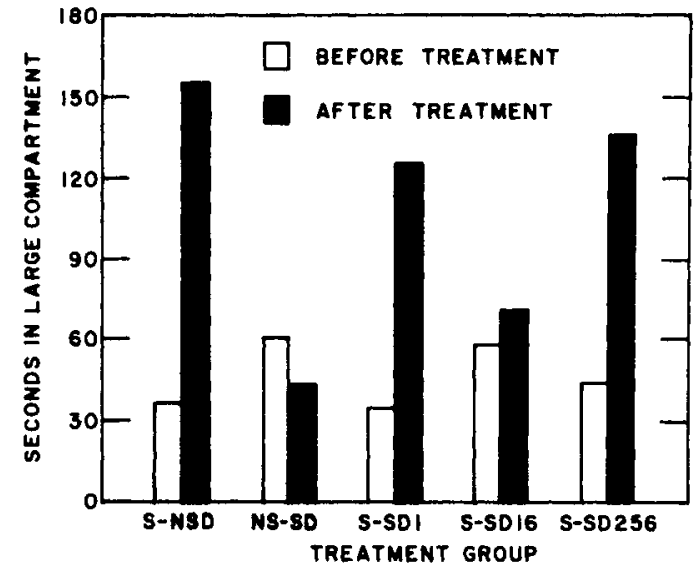

Fig. 1. Mean time in the large compartment before and after experimental treatment.

10.32, df $=4 / 70, p<.01)$. Tukey's gap test $(p=.05)$ indicated that the means fell into two significantly different clusters. That is, the NS-SD and S-SD 16 groups differed reliably from the other three. No other differences approached significance.

\section{Discussion}

As indicated by the pretreatment scores, rats tend to spend most time in the small compartment of the apparatus. This behavior was not changed appreciably by SD alone (Group NS-SD). Shock alone (Group S-NSD) caused Ss to avoid the small compartment. Amnesia for shock is clearly shown by the S-SD 16 group since these Ss behaved similarly to the NS-SD group. This result is presumably due to interference with a consolidation process by SD. The S-SD 256 group failed to show amnesia indicating that consolidation was complete $256 \mathrm{~min}$. after shock. Of particular interest is the fact that the S-SD 1 group gave no evidence for retrograde amnesia.

The reliability of the phenomenon reported here is supported by two previous observations. First, Nutter in his unpublished study found that rats shocked in an open field showed retrograde amnesia if $\mathrm{SD}$ was initiated 4,16 , or $64 \mathrm{~min}$. after shock. Little or no amnesia was found in animals given SD only $1 \mathrm{~min}$. after shock. However, the interpretation of Nutter's data was complicated by the fact that SD alone produced a marked increase in open field activity. Second, Burěs \& Bureśová (1963), using a test procedure similar to the one used in the present study, found that animals given SD $2 \mathrm{hr}$. after shock spent more than twice as much time in the small compartment (indicating amnesia) than did animals given SD immediately after shock. These authors, however, did not comment on this aspect of their data.

Two hypotheses may be offered to account for the failure to find amnesia in the S-SD 1 group. First, it is possible that immediately preceding shock protects rats from the usual effects of $\mathrm{KC1}$. There is some evidence that foot shock may protect rats from extensor tonus due to electroconvulsive strength shock (Weissman, 1964). However, this explanation does not appear very plausable in the present situation. The KC1 was in place for $4 \mathrm{hr}$. and from the data reported here it is clear that rats are not protected from $\mathrm{KCl}$ applied only $16 \mathrm{~min}$. after shock.

An alternative hypothesis postulates a three stage information storage process. During the first stage, information is held in a short-term storage, presumably subcortical. Information is not lost during this stage if the cortex is depressed but the trace may be disrupted by ECS. If the cortex is depressed, information is retained in the temporary storage until normal cortical functioning returns. At the start of the second stage a few minutes after the training-trial, information is released, as an active trace, to a permanent storage involving the cortex. During this phase, the trace will be lost as a result of SD. The start of the third stage is defined by the completion of consolidation so that the trace may no longer be disrupted by ECS or SD.

Independent support for this hypothesis comes from a study by Barondes \& Cohen (1966) who found that puromycin injected into the temporal cortex of mice did not affect retention for several minutes after training but did produce a nearly complete loss in $180 \mathrm{~min}$. They concluded that information storage may be a "...triphasic or multiphasic process rather than a biphasic one."

\section{References}

Barondes, D. H., \& Cohen, H. D. Puromycin effect on successive phases of memory storage. Science, 1966, 151, 594-595.

Bures, J., \& Burešová, O. Cortical spreading depression as a memory disturbing factor. J. comp. physiol. Psychol., 1963, 56, 268-272.

Heriot, J. T., \& Coleman, P. D. The effect of electroconvulsive shock on retention of a modified "one-trial" conditioned avoidance. J. comp. physiol. Psychol., 1962, 55, 1082-1084.

Madsen, M. C., \& McGaugh, J. L. The effect of ECS on one-trial avoidance learning. J. comp. physiol. Psychol, 1961, 54, 522523.

Pearlman, C. A., \& Jarvik, M. E. Retrograde amnesia produced by spreading cortical depression. Fed. Proc., 1961, 20, 340.

Pearlman, C. A., Sharpless, S. K., \& Jarvik, M. E. Retrograde amnesia produced by anesthetic and convulsant agents. $J$. comp. physiol. Psychol., 1961, 54, 109-112.

Weissman, A. Retrograde amnesia effects of supramaximal electroconvulsive shock on one-trial acquisition in rats: A replication. J. comp. physiol. Psychol., 1964, 57, 248-250.

\section{Notes}

1. This research was supported by Canadian National Research Council grant APA68. The author is indebted to Richard Nutter whose work forms the basis for the present study and to Donald Sneddon who tested animals.

2. Now at San Jose State College. 